\title{
Radiation therapy for gastric mucosa-associated lymphoid tissue lymphoma: dose-volumetric analysis and its clinical implications
}

\author{
Hyeon Woo Lim, MD', Tae Hyun Kim, MD1, II Ju Choi, MD², Chan Gyoo Kim, MD², Jong Yeul Lee, MD², \\ Soo Jeong Cho, MD², Hyeon Seok Eom, MD³ Sung Ho Moon, MD', Dae Yong Kim, MD' \\ ${ }^{1}$ Proton Therapy Center, ${ }^{2}$ Center for Gastric Cancer, ${ }^{3}$ Center for Specific Organs Cancer, Research Institute and Hospital, \\ National Cancer Center, Goyang, Korea
}

\begin{abstract}
Purpose: To assess the clinical outcomes of radiotherapy (RT) using two-dimensional (2D) and three-dimensional conformal RT (3D-CRT) for patients with gastric mucosa-associated lymphoid tissue (MALT) Iymphoma to evaluate the effectiveness of involved field RT with moderate-dose and to evaluate the benefit of 3D-CRT comparing with 2D-RT.

Materials and Methods: Between July 2003 and March 2015, 33 patients with stage IE and IIE gastric MALT Iymphoma received RT were analyzed. Of 33 patients, 17 patients (51.5\%) were Helicobacter pylori (HP) negative and 16 patients (48.5\%) were HP positive but refractory to HP eradication (HPE). The 2D-RT $(n=14)$ and 3D-CRT $(n=19)$ were performed and total dose was 30.6 Gy/17 fractions. Of 11 patients who RT planning data were available, dose-volumetric parameters between 2D-RT and 3D-CRT plans was compared.

Results: All patients reached complete remission (CR) eventually and median time to CR was 3 months (range, 1 to 15 months). No local relapse occurred and one patient died with second primary malignancy. Tumor response, survival, and toxicity were not significantly different between 2D-RT and 3D-CRT ( $p>0.05$, each). In analysis for dose-volumetric parameters, $D_{\max }$ and $\mathrm{Cl}$ for PTV were significantly lower in 3D-CRT plans than 2D-RT plans $\left(p<0.05\right.$, each) and $D_{\text {mean }}$ and $V_{15}$ for right kidney and $D_{\text {mean }}$ for left kidney were significantly lower in 3D-CRT than 2D-RT ( $p<0.05$, each).

Conclusion: Our data suggested that involved field RT with moderate-dose for gastric MALT lymphoma could be promising and 3D-CRT could be considered to improve the target coverage and reduce radiation dose to the both kidneys.
\end{abstract}

Keywords: Lymphoma, Stomach, Radiotherapy

\section{Introduction}

Mucosa-associated lymphoid tissue (MALT) Iymphoma is neoplasm originated from marginal zone B cells that primarily or secondarily involves the gastrointestinal tract, lungs, salivary glands, thyroid, ocular adnexa, and liver and skin. Among these sites, the stomach is the most frequently involved in case of MALT lymphoma (50\%-60\% of all cases) and Helicobacter pylori (HP) infection is known to be the most important causative factor, with a positive rate of approximately 90\% in early stage gastric MALT Iymphoma patients at diagnosis $[1,2]$. After HP eradication (HPE), a

Received 10 July 2016, Revised 27 July 2016, Accepted 4 August 2016.

Correspondence: Tae Hyun Kim, MD, Proton Therapy Center, Research Institute and Hospital, National Cancer Center, 323 Ilsan-ro, Ilsandong-gu, Goyang 10408, Korea. Tel: +82-31-920-1725, Fax: +82-31-920-0149, E-mail: k2onco@naver.com

(C) This is an Open Access article distributed under the terms of the Creative Commons Attribution Non-Commercial License (http://creativecommons.org/ licenses/by-nc/4.0/) which permits unrestricted non-commercial use, distribution, and reproduction in any medium, provided the original work is properly cited.

www.e-roj.org 
remission rate of approximately $80 \%$ can be achieved in stage I patients $[3,4]$, but only $45 \%$ to $56 \%$ in stage || $[2,5,6]$. As may be expected, HPE alone a much lower response rate in patients with HP negative $[2,5]$. The management options for gastric MALT Iymphoma patients with refractory to HPE or HP negative include surgery, chemotherapy, radiotherapy (RT), and immunotherapy. However, because randomized studies have not been performed and difficulty of direct comparison among the studies due to heterogeneity of treatments and relative small sample size, the most appropriate management strategy for gastric MALT Iymphoma patient with refractory to HPE refractory or HP negative is unclear to date.

Previous studies for RT, using a relative high dose of 36 Gy up to 45 Gy (mostly 40 Gy) or large field including whole abdomen or regional and/or para-aortic lymph nodes showed that RT could be curative in patients with localized stage IE or IIE MALT Iymphoma [7-10]. Conceptually, because gastric MALT lymphoma has a natural history of slow progression, remaining confined to the stomach even over several years, local RT could be an effective therapeutic modality with organ preservation. Recent several studies, using moderate-dose RT (about $30 \mathrm{~Gy}$ ) and involved field RT including stomach and perigastric lymph nodes, have shown promising results, such as 93\%-100\% of remission rate and 96\%-100\% of overall survival (OS) [11-19]. In addition, recent technological innovations in RT planning and delivery, such as three-dimensional conformal RT (3D-CRT) or intensity modulated RT, have made possible the conformal delivery of radical radiation to the tumor and decrease the radiation to the normal tissues, including kidney, comparing two-dimensional RT (2D-RT) with parallel opposed fields $[18,20]$. However, due to lack of randomized and direct comparative studies, optimal radiation dose and target volume of RT for gastric MALT Iymphoma have not yet clearly defined. Therefore, we performed a retrospective analysis to assess the clinical outcomes, such as tumor response, survival, and toxicity, of RT using 2D-RT and 3D-CRT techniques for gastric MALT Iymphoma patients with refractory to HPE or HP negative to evaluate the effectiveness of involved field RT with moderate-dose and to evaluate the benefit of 3D-CRT comparing with 2D-RT.

\section{Materials and Methods}

\section{Patients}

Between July 2003 and March 2015, 33 patients with localized gastric MALT Iymphoma received RT and were included in this study. All of the patients were histologically diagnosed with gastric MALT Iymphoma by endoscopic biopsy and subsequently underwent a systemic workup including complete blood cell counts, liver function test, renal function test, lactate dehydrogenase, chest radiographs, abdominopelvic computed tomography (CT) and/or gastric endoscopic ultrasonography. HP infection was determined by histologic examination, rapid urease test, urea breath test, and/or serum anti-HP immunoglobulin G antibody. MALT Iymphomas were classified according to Ann Arbor classification, modified by Musshoff [21], and international prognostic index (IPI) score [22]. This study was performed in accordance with the guidelines of National Cancer Center Institutional Review Board, and informed consent was not required due to retrospective study.

\section{Radiation therapy}

All patients were asked to overnight fasting before CT simulation and treatment. To identify stomach accurately on CT scan, the patients swallowed $100 \mathrm{~mL}$ of oral contrast media before CT scan. All patients underwent CT simulation (Lightspeed RT; GE Healthcare, Waukesha, WI, USA) in a supine position with arm above the head and immobilized using an arm-up holder. Contrast-enhanced CT images were acquired with 2.5-4 $\mathrm{mm}$ thickness from the level of the 7 th thoracic spine to the lower level of 4th lumbar spine under shallow respiration and were transferred to Eclipse treatment planning system (Varian Medical Systems, Palo Alto, CA, USA). The contours for targets and organs at risk (OARs) were delineated. The clinical target volume (CTV) was defined as the entire stomach and suspicious involved regional lymph nodes. The planning target volume (PTV) was defined as the CTV plus $1-1.5 \mathrm{~cm}$ margin in all direction. Additional $1 \mathrm{~cm}$ margin was given to the craniocaudal direction to compensate respiratory stomach motion. 2D-RT ( $n=14)$ and 3D-CRT plans ( $n=19)$, according to the physicians' preferences, were performed using anterior-posterior opposing two fields (Fig. 1A and B) and three or four coplanar fields (Fig. 1C and D), respectively, and the beam weights of the plans were optimized to minimize the maximum dose within target volume and OARs. RT was delivered using a linear accelerator with $15 \mathrm{MV} X$-rays in a daily fraction of $1.8 \mathrm{~Gy}, 5$ days/week, with a total dose to isocenter of $30.6 \mathrm{~Gy}$. Reproducibility of the empty gastric size shape and position was confirmed in a simulation, first day and every week of treatment and the patients were treated in the early morning under overnight fasting.

At the time of analysis, RT planning data were available in 11 patients. In these patients two sets of plans were performed for each patient, one each for 2D-RT and 3D-CRT. The PTV 

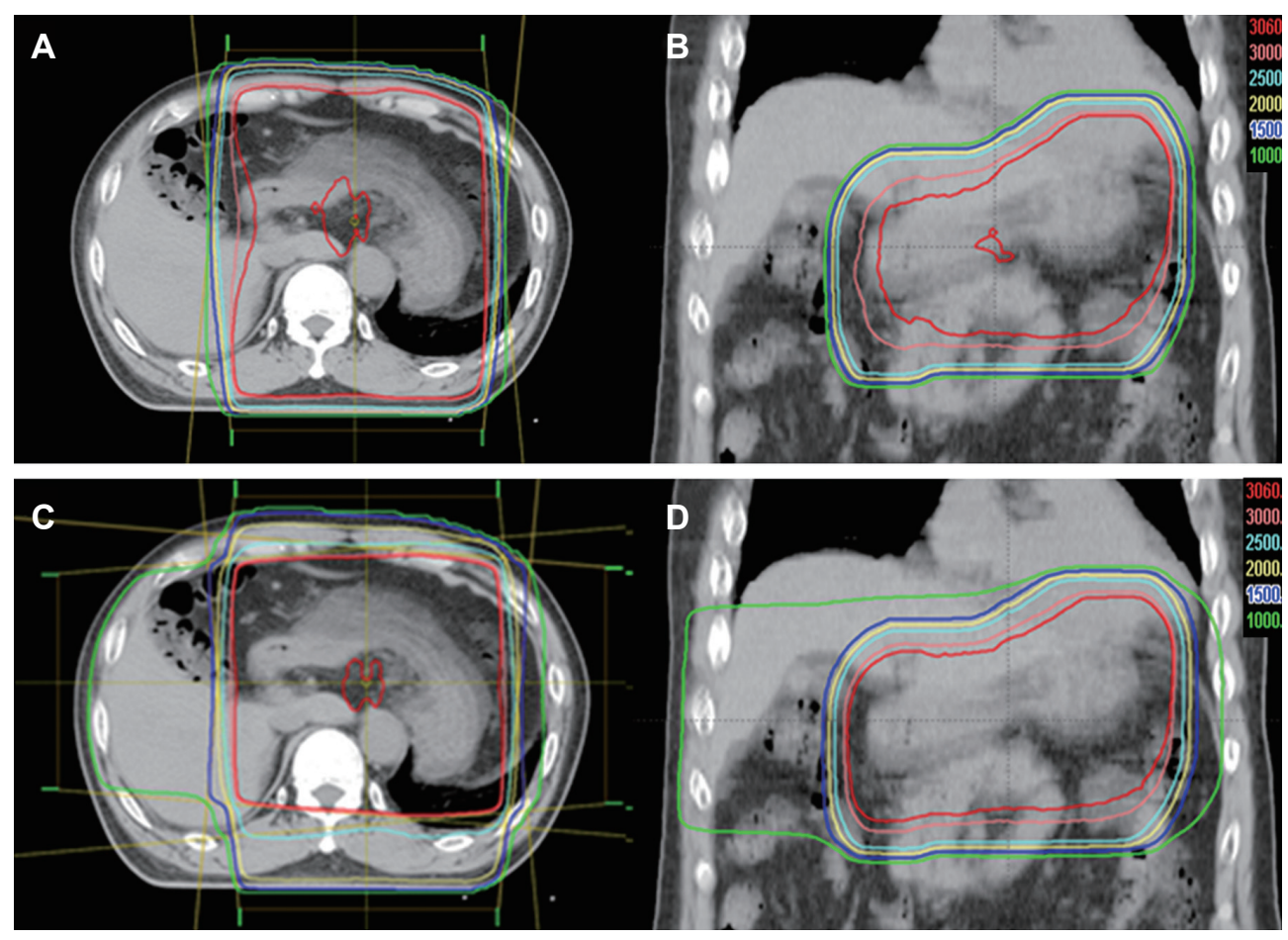

Fig. 1. Axial (A) and coronal (B) computed tomography (CT) images of two-dimensional plan for radiotherapy with anteriorposterior opposing two fields and axial (C) and coronal (D) CT images of three-dimensional plan for radiotherapy with four coplanar fields.

and margins were identically used for 2D-RT and 3D-CRT in each patient. Dose-volumetric analysis was performed using dose volume histograms (DVHs) of the treatment plans for individual patients. To compare PTV coverages, maximum dose $\left(D_{\text {max }}\right)$, mean dose $\left(D_{\text {mean }}\right)$ and percent volume of PTV receiving $95 \%$ of prescription dose $\left(V_{95 \%}\right)$ were calculated. Other calculated parameters included the conformity index (CI), defined as the volume within 95\% of the prescribed dose divided by the PTV volume, and the homogeneity index (HI), defined as the minimum dose delivered to $5 \%$ of the PTV divided by the minimum dose delivered to $95 \%$ of the PTV [23]. $\mathrm{Cl}$ and $\mathrm{HI}$ values closer to 1 indicated better conformity and homogeneity, respectively, of the PTV. Parameters used to compare sparing of OARs, such as both kidney, liver and small bowel, included mean dose $\left(D_{\text {mean }}\right)$ and $V_{15}$, defined as the percentage of volume which is receiving $15 \mathrm{~Gy}$.

\section{Follow up and statistical analysis}

During the course of RT, patients were seen by physicians at least once a week to evaluate patient complaints including change of body weight. Tumor responses were assessed by endoscopy and histologic evaluation at 1-3 month of completion of RT, every 3 months for the first 2 years and every 6 months thereafter using the World Health Organization Response Criteria [24]. Complete remission (CR) was defined as the total disappearance of clinical evidence for lymphoma and an absence of histologic evidence for lymphoma on biopsy specimens. Partial remission (PR) was defined as a tumor reduction of at least 50\%, no change (NC) was defined as variation within either disease or $25 \%$ increase in tumor size, and progressive disease (PD) was defined as a $25 \%$ increase in tumor size. Toxicity was assessed using Common Terminology Criteria for Adverse Events ver. 3.0 (CTCAE v3.0).

Local progression was defined as a regrowth or new tumor within the treated volume. Local progression-free survival (LPFS), relapse-free survival (RFS), and OS were defined as the intervals from the date of the start of RT to the date of detection of local progression, any detection of relapse of MALT Iymphoma or transformation to a diffuse large $B$ cell lymphoma (DLBCL), and death or last follow-up, respectively. The probability of survival was calculated using the KaplanMeier method. Differences in toxicities and body weight change between 2D-RT and 3D-CRT were compared by Fisher exact test and Mann-Whitney $U$ test, respectively, and differences in the dose volumetric parameters between 2DRT and 3D-CRT plans were compared by Wilcoxon signedrank test. All statistical analyses were two-sided and were performed using STATA software ver. 9.0 (Stata Co., College Station, TX, USA). A p-value $<0.05$ indicated statistical significance. 
Table 1. Patient characteristics

\begin{tabular}{|c|c|c|c|c|}
\hline Characteristic & Total & 2D-RT & 3D-CRT & $p$-value \\
\hline Gender & & & & $0.491^{\text {a) }}$ \\
\hline Male & $17(51.5)$ & $6(42.9)$ & $11(52.9)$ & \\
\hline Female & $16(48.5)$ & $8(57.1)$ & $8(42.1)$ & \\
\hline \multicolumn{5}{|l|}{ Age (yr) } \\
\hline Median (range) & $51(17-74)$ & $52(17-74)$ & $51(33-60)$ & $0.558^{b)}$ \\
\hline$\leq 60$ & $29(87.8)$ & $12(85.7)$ & 17 (89.5) & $0.744^{\mathrm{a})}$ \\
\hline$>60$ & $4(12.2)$ & 2 (14.3) & 2 (10.5) & \\
\hline HP status & & & & $0.728^{\mathrm{a})}$ \\
\hline Positive & $16(48.5)$ & $6(42.9)$ & $10(52.6)$ & \\
\hline Negative & $17(51.5)$ & $8(57.1)$ & $9(47.4)$ & \\
\hline Clinical stage & & & & $0.561^{\mathrm{a})}$ \\
\hline IE & 30 (90.9) & $12(85.7)$ & $18(94.7)$ & \\
\hline IIE & 3 (9.1) & 2 (14.3) & $1(5.3)$ & \\
\hline IPI score & & & & $0.241^{\mathrm{a})}$ \\
\hline 0 & 27 (81.8) & $10(71.4)$ & 17 (89.5) & \\
\hline 1 & $5(15.2)$ & $3(21.4)$ & $2(10.5)$ & \\
\hline 2 & $1(3.0)$ & $1(7.2)$ & $0(0)$ & \\
\hline Size $(\mathrm{cm})$ & & & & $0.074^{\mathrm{a})}$ \\
\hline$\leq 3$ & 11 (33.3) & $3(21.4)$ & $8(42.1)$ & \\
\hline $3.1-7$ & $9(27.3)$ & $7(50.0)$ & $2(10.5)$ & \\
\hline$>7$ & $1(3.0)$ & $0(0)$ & $1(5.3)$ & \\
\hline Multiple or diffuse & $12(36.4)$ & $4(28.6)$ & $8(42.1)$ & \\
\hline Location of tumor & & & & $0.248^{\mathrm{a})}$ \\
\hline Body & $18(54.5)$ & $10(71.4)$ & $8(42.1)$ & \\
\hline Pylorus-antrum & $2(6.1)$ & $1(7.2)$ & $1(5.3)$ & \\
\hline Fundus-cardia & $1(3.0)$ & $0(0)$ & $1(5.3)$ & \\
\hline Multiple or diffuse & $12(36.4)$ & $3(21.4)$ & $9(47.3)$ & \\
\hline Depth of invasion & & & & $0.588^{\mathrm{a})}$ \\
\hline Mucosa & $4(12.1)$ & $2(14.3)$ & $2(10.5)$ & \\
\hline Submucosa & $12(36.4)$ & $7(50.0)$ & $5(26.3)$ & \\
\hline Muscularis & $2(6.0)$ & $0(0)$ & $2(10.5)$ & \\
\hline Subserosa/serosa & $3(9.1)$ & $1(7.1)$ & $2(10.5)$ & \\
\hline Unknown & $12(36.4)$ & $4(38.6)$ & $8(42.2)$ & \\
\hline
\end{tabular}

Values are presented as number (\%).

2D-RT, two-dimensional radiotherapy; 3D-CRT, three-dimensional conformal radiotherapy; HP, Helicobacter pylori; IPI, international prognostic index.

${ }^{a)}$ Fisher exact test (two-tail). ${ }^{\text {b) }}$ t-test.

\section{Results}

\section{Patient characteristics}

Patient characteristics are summarized in Table 1. Median age of the patients was 51 years with a range of 17 to 74 . Of 33 patients, 17 (51.5\%) patients were HP negative and 16 (48.5\%) patients were HP positive but refractory to HPE. The patients had localized disease with stage IE $(n=30,90.9 \%)$ and IIE $(n=$ 3, 9.1\%), and IPI score distribution was: 0 in 27 patients (81.8\%), 1 in 5 patients (15.2\%), and 2 in 1 patient (3\%). Most common location of disease site was body $(n=18,54.5 \%)$. There were no significant differences between 2D-RT and 3D-CRT (Table 1).

\section{Response, local progression free survival, relapse free survival overall survival}

Median follow up duration was 4.2 years (range, 1.0 to 12.1 years). All patients reached $\mathrm{CR}$ eventually and median time to CR was 3 months (range, 1 to 15 months): 31 patients (93.9\%) showed CR within 6 months and remaining 2 patients reached $\mathrm{CR}$ at 10 and 15 month after RT, respectively (Fig. 2). At the time of analysis, no local relapse occurred and second primary malignancies developed in 3 patients. One patient developed 
Table 2. Comparison of body weight change between patients receiving 2D-RT and 3D-CRT

\begin{tabular}{lccc}
\hline \multicolumn{1}{c}{ Body weight change } & 2D-RT & 3D-CRT & p-value \\
\hline Absolute change $(\mathrm{kg})$ & $-1.0 \pm 0.9(-2.0$ to 0.7$)$ & $-0.9 \pm 1.2(-3.6$ to 0.7$)$ & 0.733 \\
Relative change $(\%)$ & $-1.6 \pm 1.5(-3.6$ to 1.2$)$ & $-1.3 \pm 1.8(-4.7$ to 1.4$)$ & 0.957 \\
\hline
\end{tabular}

Values are presented as mean \pm standard deviation (range).

2D-RT, two-dimensional radiotherapy; 3D-CRT, three-dimensional conformal radiotherapy; absolute change, body weight at completion of radiotherapy (RT) - body weight at pre-RT; relative change, [(body weight at completion of RT - body weight at pre-RT) / body weight at pre-RT] $\times 100$.

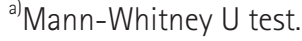

Table 3. Comparison of acute toxicity between patients receiving 2D-RT and 3D-CRT

\begin{tabular}{|c|c|c|c|c|c|c|c|}
\hline & \multicolumn{3}{|c|}{$2 \mathrm{D}-\mathrm{RT}(\mathrm{n}=14)$} & \multicolumn{3}{|c|}{ 3D-CRT $(n=19)$} & \multirow[b]{2}{*}{$p$-value } \\
\hline & Grade 0 & Grade 1 & Grade 2 & Grade 0 & Grade 1 & Grade 2 & \\
\hline \multicolumn{8}{|l|}{ Gastrointestinal } \\
\hline Anorexia & 9 & 3 & 2 & 14 & 4 & 1 & 0.853 \\
\hline Nausea/vomiting & 1 & 7 & 6 & 4 & 10 & 5 & 0.506 \\
\hline Diarrhea & 14 & 0 & 0 & 17 & 2 & 0 & 0.496 \\
\hline Pain & 9 & 3 & 2 & 16 & 3 & 0 & 0.172 \\
\hline \multicolumn{8}{|l|}{ Hematologic } \\
\hline WBC & 9 & 1 & 4 & 13 & 4 & 2 & 0.202 \\
\hline $\mathrm{Hb}$ & 12 & 2 & 0 & 15 & 4 & 0 & 1.000 \\
\hline Platelet & 14 & 0 & 0 & 19 & 0 & 0 & 1.000 \\
\hline \multicolumn{8}{|l|}{ Hepatic } \\
\hline AST/ALT & 11 & 3 & 0 & 19 & 0 & 0 & 0.067 \\
\hline \multicolumn{8}{|l|}{ Renal } \\
\hline Creatinine & 13 & 1 & 0 & 19 & 0 & 0 & 0.424 \\
\hline
\end{tabular}

2D-RT, two-dimensional radiotherapy; 3D-CRT, three-dimensional conformal radiotherapy; WBC, white blood cell; Hb, hemoglobin; AST, aspartate transaminase; ALT, alanine transaminase.

${ }^{a)}$ Fisher exact test, two-tail.

DLBCL of the tonsil after 43 months of RT and has remained alive without disease after chemotherapy. Two patients developed second primary malignancies in stomach: one patient was diagnosed as early stage gastric adenocarcinoma at 22 months after RT and was successfully salvaged by endoscopic submucosal dissection and the other patient developed adenosquamous cell carcinoma at 13 months after RT, which caused death at 8 months after the development. No local relapse occurred and 5-year LPFS, RFS, OS rates were 100\%, 100\%, and 97\%, respectively. There were no differences in 5-year LPFS, RFS, and OS between 2D-RT and 3D-CRT (100\% vs. $100 \%, p=1.000$; and $100 \%$ vs. $100 \%, p=1.000$; and $92.9 \%$ vs. $100 \%, p=0.317$, respectively).

\section{Toxicities}

To compare the tolerability between 2D-RT and 3D-CRT, body weight change of the patients before and after RT was compared (Table 2). Absolute (relative) mean decrease of body weight of the patients was $1.0 \pm 0.9 \mathrm{~kg}(1.6 \pm 1.5 \%)$ in $2 \mathrm{D}-\mathrm{RT}$ and $0.9 \pm 1.2 \mathrm{~kg}(1.3 \pm 1.8 \%)$ in 3D-CRT $(p>0.05$, each) and these differences were not significant ( $p>0.05$, each). Comparisons of acute gastrointestinal, hematologic, hepatic, and renal toxicities between 2D-RT and 3D-CRT are summarized in Table 3. Within 3 months after RT, acute toxicities were transient, easily manageable, and caused no interruption in treatment course. Of the 33 patients, grade 2 nausea or vomiting, anorexia, and abdominal pain, leukopenia were observed in 11 patients (33.3\%), 3 patients (9.1\%), 2 patients $(6.1 \%)$, and 6 patients $(18.2 \%)$, respectively. The distributions of acute gastrointestinal, hematologic, hepatic, and renal toxicities were not significantly different between 2D-RT and 3D-CRT ( $p>0.05$, each) (Table 3). Treatment-related late gastrointestinal, hematologic, hepatic and renal toxicities, occurring after 3 months after completion of RT, were not observed. 
Table 4. Comparison of dose-volumetric parameters between patients receiving $2 \mathrm{D}-\mathrm{RT}$ and $3 \mathrm{D}-\mathrm{CRT}$

\begin{tabular}{lrrr}
\hline \multicolumn{1}{c}{ Factor } & 2D-RT & 3D-CRT & p-value ${ }^{\mathrm{a}}$ \\
\hline $\mathrm{PTV}$ & & & \\
$\mathrm{D}_{\text {max }}(\%)$ & $106.2 \pm 2.5$ & $105.1 \pm 1.5$ & 0.021 \\
$\mathrm{D}_{\text {mean }}(\%)$ & $101.8 \pm 1.6$ & $102.4 \pm 1.2$ & 0.052 \\
$\mathrm{~V}_{95 \%}(\%)$ & $100.0 \pm 0.3$ & $100.0 \pm 0.0$ & 0.059 \\
$\mathrm{Cl}$ & $8.3 \pm 3.4$ & $5.1 \pm 1.9$ & 0.003 \\
$\mathrm{HI}$ & $1.05 \pm 0.02$ & $1.03 \pm 0.01$ & 0.136 \\
Right kidney (\%) & & & \\
$\mathrm{D}_{\text {mean }}$ & $35 \pm 18$ & $26 \pm 12$ & 0.010 \\
$\mathrm{~V}_{15}$ & $31 \pm 19$ & $28 \pm 17$ & 0.013 \\
Left kidney (\%) & & & \\
$\mathrm{D}_{\text {mean }}$ & $56 \pm 30$ & $42 \pm 21$ & 0.011 \\
$\mathrm{~V}_{15}$ & $52 \pm 30$ & $47 \pm 27$ & 0.108 \\
Liver (\%) & & & \\
$\mathrm{D}_{\text {mean }}$ & $28 \pm 6$ & $50 \pm 6$ & 0.003 \\
$\mathrm{~V}_{15}$ & $26 \pm 8$ & $32 \pm 20$ & 0.003 \\
Small bowel $(\%)$ & & & \\
$\mathrm{D}_{\text {mean }}$ & $76 \pm 20$ & $76 \pm 20$ & 0.758 \\
$\mathrm{~V}_{15}$ & $76 \pm 22$ & $76 \pm 23$ & 0.442 \\
\hline
\end{tabular}

Values are presented as mean \pm standard deviation.

2D-RT, two-dimensional radiotherapy; 3D-CRT, three-dimensional conformal radiotherapy; PTV, planning target volume; $D_{\max }$ maximum dose; $D_{\text {mean }}$ mean dose; $V_{95 \%}$ percentage of the PTV receiving 95\% of the prescription dose; $\mathrm{Cl}$, conformity index; $\mathrm{HI}$, homogeneity index; $V_{15}$, percentage of irradiated volume receiving $15 \mathrm{~Gy}$ or higher.

${ }^{a)}$ Wilcoxon signed-rank test.

\section{Dose-volumetric parameters}

The dose-volumetric parameters between 2D-RT and 3D-CRT plans are summarized in Table 3. Among the dose volumetric parameters for PTV coverage, the $\mathrm{D}_{\max }$ and $\mathrm{Cl}$ were significantly lower in 3D-CRT plans than 2D-RT plans ( $p<0.05$, each), but $D_{\text {mean }}, V_{95 \%}$ and $\mathrm{HI}$ were not significantly different between two plans ( $p>0.05$, each) (Table 4). Among the dose volumetric parameters for OARs, $D_{\text {mean }}$ and $V_{15}$ for right kidney and $D_{\text {mean }}$ for left kidney were significantly lower in 3D-CRT plans than $2 D-R T$ plans ( $<<0.05$, each), whereas $D_{\text {mean }}$ and $V_{15}$ for liver was significantly lower in 2D-RT plans than 3D-CRT plans ( $p<$ 0.05 , each). There were no differences in $D_{\text {mean }}$ and $V_{15}$ for small bowel between 2D-RT and 3D-CRT plans ( $p<0.05$, each).

\section{Discussion and Conclusion}

The management strategy for gastric MALT Iymphoma patients with HP negative or refractory to HPE is not welldefined. Pooled data analysis assessed the efficacy of different oncologic therapeutic approaches to treat localized gastric

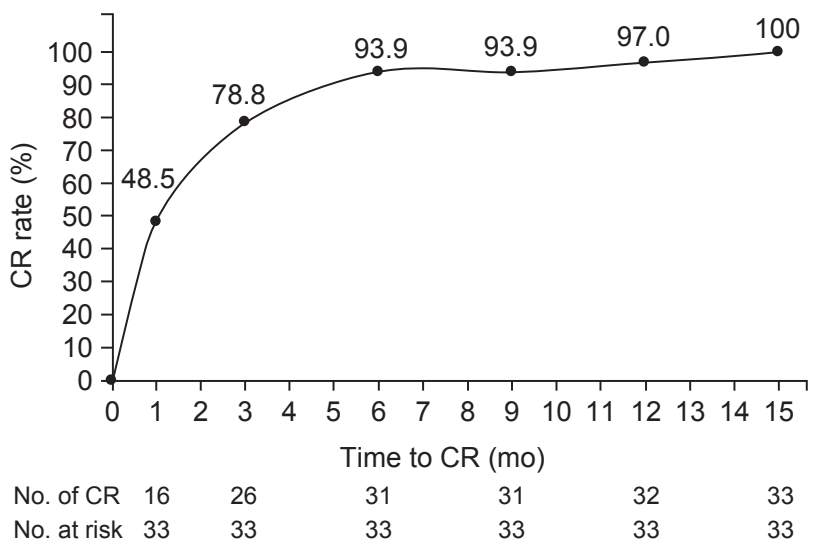

Fig. 2. Overall time to complete remission (CR) after radiotherapy.

MALT Iymphoma refractory to HPE showed a slightly higher CR rate following RT as compared with chemotherapy (97.3\% vs. $85.3 \%, p=0.007)$, being similar to surgery (97.3\% vs. $92.5 \%, p$ $=0.2$ [) [5]. Although no data are available directly comparing RT and chemotherapy, treatment guidelines recommend a stagedependent approach, favoring RT for localized disease and chemotherapy for advanced stage of the disease [15]. Concepts concerning RT in gastric MALT lymphoma have changed significantly over time. In the past, the irradiation target volume was the entire abdomen followed by an additional dose to the entire stomach and the perigastric lymph nodes [7-11,25]. Knowledge concerning the pattern of spread of gastric MALT Iymphoma had increase through surgical series and the user of modern radiological examinations. Localized gastric MALT Iymphoma tends to be confined to the gastric wall and lymph node involvement may be observed, but in the vast majority only restricted to the perigastric lymph nodes $[4,26,27]$. Therefore, the target volume has been reduced to the stomach and the perigastric lymph nodes $[14,16,18,28-30]$. In addition, MALT Iymphomas have been reported to highly sensitive to RT [7-10], and, in several studies using moderatedose of RT for gastric MALT Iymphoma, response rates between 93\% and $100 \%$ and $0 \mathrm{~S}$ rates between $96 \%$ and 100\% based on a median follow-up of 3.3-7.2 years were reported [11-19]. Similarly, in present study, involved field RT with moderatedose (30.6 Gy) for gastric MALT lymphoma patients with HP negative or refractory to HPE showed promising outcomes, such as 100\% of CR rates, 100\% of 5-year LPFS rates, and 97\% of 5-year OS.

The optimal time of response evaluation after RT for gastric MALT Iymphoma has not been well-defined. Kim et al. [28] have mentioned that 95.1\% (61 of 64) patients achieved a CR was at 1-2 months after RT and eventually all patients 
achieved a CR at 4-5 months after RT. In present study, 31 of 33 patients (93.9\%) showed CR within 6 months and remaining 2 patients (6.1\%) reached $\mathrm{CR}$ at 10 and 15 month after RT, respectively (Fig. 2). Because of the indolent nature of gastric MALT Iymphoma, it has been known that CR is obtained usually within 6-12 months from HPE and thus second treatment can be postponed up to 24 months after HPE [15]. Considering these findings, first evaluation of lymphoma regression might be performed 3 months after completion of RT and, in cases which do not achieve a $C R$, further salvage treatment could be postponed up to about 12-24 months after completion of RT.

Chronic HP infection is the well-known risk factor for development of gastric carcinoma as well as gastric MALT Iymphoma. In present study, 2 patients (6.1\%) with HPE refractory gastric MALT Iymphoma developed metachronous gastric adenocarcinoma at 13 months and 22 months after RT with CR of previous gastric MALT Iymphoma. Although gastric MALT Iymphoma and HP infection became a CR after RT, chronic active gastritis was continuously observed in histologic examination. Conceptually, even after gastric MALT Iymphoma and HP infection became CR after RT, chronic atrophic gastritis and intestinal metaplasia induced by previous chronic $\mathrm{HP}$ infection could be a cause of gastric carcinoma. Ono et al. [30] have reported that 5\% of metachronous gastric carcinoma after remission of gastric MALT Iymphoma and it was higher than incidence of gastric carcinoma in Japanese general population. Capelle et al. [31] reported that the risk of developing gastric carcinoma in patients with gastric MALT lymphoma were shown to be 6 times higher than in the general population. This risk seems unrelated to the treatment modalities (i.e., antibiotics, RT, chemotherapy, etc.) but likely related to associated with HP gastritis $[12,16,28,31]$. However, long latent period of the development of metachronous gastric carcinoma after remission of gastric MALT Iymphoma, regular follow-up endoscopy after remission of gastric MALT Iymphoma should be recommended for detection of metachronous gastric carcinoma at an early stage.

The major concern against stomach irradiation is the risk of perforation and bleeding due to rapid tumor lysis and the untoward side effects to the kidney. However, according to previous reports, the incidence of $\mathrm{RT}$-related gastric perforation and bleeding was $4 \%$ or less $[12,32,33]$ and it is expected that the risk may be much lower in patients with early stage gastric MALT Iymphoma treated with RT using moderate-dose and involved field. Similarly, in recent several studies $[16,18,19,28]$ and present study, acute side effects of RT to the stomach consisted mainly of transient nausea vomiting, anorexia and no RT-related perforation and bleeding was observed. In addition, RT in a fasting status, as in our and other institutional protocols $[15-18,28]$, can minimize the stomach distension and subsequently reduce the irradiated volume to normal tissue and local RT with the use of 3D-CRT or intensity modulated RT techniques has the particular advantage of reducing the radiation dose to the kidneys, particularly on the left side $[17,20,34]$. Similarly, in present study, although actual incidences of various toxicities, such as change of body weight, gastrointestinal, hematologic, hepatic, and renal toxicities, were not significantly between 2D-RT and 3D-CRT, 3D-CRT improved the target coverage, lower $\mathrm{Cl}$ and $D_{\text {max }}$ and reduced radiation to both kidney, lower $D_{\text {mean }}$ and $V_{15}$ for right side and lower $D_{\text {mean }}$ for left side, comparing with 2DRT (Table 3).

This study has some limitations. First, it is a retrospective study with relative small sample size $(n=33)$ and relative short follow-up time (median, 4.2 year) and gene abnormality, i.e., $t(11 ; 18)(q 21 ; q 21)$ which is one of well-known poor prognostic factors, was not considered. Second, dose uncertainty resulting from stomach motion during respiration and reproducibility of empty gastric size, shape and position during treatment was not thoroughly evaluated in present study. Third, optimal timing of RT has not been determined for cases refractory to HPE. The standard management for patients with for gastric MALT Iymphoma is follow-up endoscopy at 3 and 6 months after HPE and patients who have PR and remain HP positive has been recommend to receive a second course of antibiotics before preceding to more definitive treatment [15]. In present study, of 16 patients who were HP positive, 7 patients (43.8\%) received $\mathrm{RT}$ due to residual disease at 6 months after HPE. Considering the indolent nature of gastric MALT Iymphoma, some controversy exists about the point at which to declare failure of HPE. Therefore, our results should be interpreted in considering aforementioned limitations and further large scaled and comprehensive studies should be warranted.

In conclusion, our data suggested that involved field RT with moderate-dose for gastric MALT Iymphoma patients with HP negative or refractory to HPE could be promising and 3D-CRT could be considered to improve the target coverage and reduce radiation dose to the both kidneys.

\section{Conflict of Interest}

No potential conflict of interest relevant to this article was reported. 


\section{Acknowledgments}

This study was supported by National Cancer Center Grant (NCC 1610590).

\section{References}

1. Marshall BJ, Windsor HM. The relation of Helicobacter pylori to gastric adenocarcinoma and lymphoma: pathophysiology, epidemiology, screening, clinical presentation, treatment, and prevention. Med Clin North Am 2005;89:313-44.

2. Nakamura $S$, Sugiyama $T$, Matsumoto $T$, et al. Long-term clinical outcome of gastric MALT Iymphoma after eradication of Helicobacter pylori: a multicentre cohort follow-up study of 420 patients in Japan. Gut 2012;61:507-13.

3. Ahmad A, Govil Y, Frank BB. Gastric mucosa-associated lymphoid tissue lymphoma. Am J Gastroenterol 2003;98:97586.

4. Stolte $M$, Bayerdorffer $E$, Morgner $A$, et al. Helicobacter and gastric MALT lymphoma. Gut 2002;50 Suppl 3:III19-24.

5. Zullo $A_{\text {, Hassan }} C_{\text {, Cristofari }} F_{\text {, et al. Effects of Helicobacter }}$ pylori eradication on early stage gastric mucosa-associated Iymphoid tissue Iymphoma. Clin Gastroenterol Hepatol 2010;8:105-10.

6. Zinzani PL. Thoughts on the eradication of Helicobacter pylori infection in localized gastric mucosa-associated lymphoid tissue lymphoma. Leuk Lymphoma 2006;47:2013-4.

7. Koch $P$, del Valle $F$, Berdel WE, et al. Primary gastrointestinal non-Hodgkin's Iymphoma: II. combined surgical and conservative or conservative management only in localized gastric lymphoma: results of the prospective German Multicenter Study GIT NHL 01/92. J Clin Oncol 2001;19:387483.

8. Willich NA, Reinartz G, Horst EJ, et al. Operative and conservative management of primary gastric lymphoma: interim results of a German multicenter study. Int J Radiat Oncol Biol Phys 2000;46:895-901.

9. Burgers JM, Taal BG, van Heerde P, Somers R, den Hartog Jager FC, Hart AA. Treatment results of primary stage I and II non-Hodgkin's lymphoma of the stomach. Radiother Oncol 1988;11:319-26.

10. Kocher M, Muller RP, Ross D, Hoederath A, Sack H. Radiotherapy for treatment of localized gastrointestinal nonHodgkin's lymphoma. Radiother Oncol 1997;42:37-41.

11. Vrieling $C$, de Jong $D$, Boot $H$, de Boer JP, Wegman $F$, Aleman BM. Long-term results of stomach-conserving therapy in gastric MALT lymphoma. Radiother Oncol 2008;87:405-11.

12. Schechter NR, Portlock CS, Yahalom J. Treatment of mucosaassociated lymphoid tissue lymphoma of the stomach with radiation alone. J Clin Oncol 1998;16:1916-21.
13. Tsang RW, Gospodarowicz MK, Pintilie M, et al. Localized mucosa-associated lymphoid tissue lymphoma treated with radiation therapy has excellent clinical outcome. J Clin Oncol 2003;21:4157-64.

14. Tomita N, Kodaira T, Tachibana H, Nakamura T, Mizoguchi N, Takada A. Favorable outcomes of radiotherapy for early-stage mucosa-associated lymphoid tissue lymphoma. Radiother Oncol 2009;90:231-5.

15. Ruskone-Fourmestraux A, Fischbach W, Aleman BM, et al. EGILS consensus report: gastric extranodal marginal zone B-cell lymphoma of MALT. Gut 2011;60:747-58.

16. Nam TK, Ahn JS, Choi YD, et al. The role of radiotherapy in the treatment of gastric mucosa-associated lymphoid tissue lymphoma. Cancer Res Treat 2014;46:33-40.

17. Park HC, Park W, Hahn JS, et al. Low grade MALT Iymphoma of the stomach: treatment outcome with radiotherapy alone. Yonsei Med J 2002;43:601-6.

18. Park HS, Kim YJ, Yang WI, Suh CO, Lee YC. Treatment outcome of localized Helicobacter pylori-negative low-grade gastric MALT Iymphoma. World J Gastroenterol 2010;16:2158-62.

19. Teckie S, Qi S, Lovie S, et al. Long-term outcomes and patterns of relapse of early-stage extranodal marginal zone lymphoma treated with radiation therapy with curative intent. Int J Radiat Oncol Biol Phys 2015;92:130-7.

20. Della Biancia C, Hunt M, Furhang E, Wu E, Yahalom J. Radiation treatment planning techniques for lymphoma of the stomach. Int J Radiat Oncol Biol Phys 2005;62:745-51.

21. Musshoff K. Clinical staging classification of non-Hodgkin's lymphomas (author's transl). Strahlentherapie 1977;153:21821.

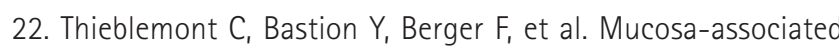
lymphoid tissue gastrointestinal and nongastrointestinal lymphoma behavior: analysis of 108 patients. J Clin Oncol 1997;15:1624-30.

23. Kataria $T$, Sharma K, Subramani V, Karrthick KP, Bisht SS. Homogeneity Index: an objective tool for assessment of conformal radiation treatments. J Med Phys 2012;37:207-13.

24. Miller $A B$, Hoogstraten $B$, Staquet $M$, Winkler $A$. Reporting results of cancer treatment. Cancer 1981;47:207-14.

25. Wirth A, Gospodarowicz M, Aleman BM, et al. Long-term outcome for gastric marginal zone lymphoma treated with radiotherapy: a retrospective, multi-centre, International Extranodal Lymphoma Study Group study. Ann Oncol 2013;24:1344-51.

26. Park W, Chang SK, Yang WI, et al. Rationale for radiotherapy as a treatment modality in gastric mucosa-associated lymphoid tissue lymphoma. Int J Radiat Oncol Biol Phys 2004;58:1480-6.

27. Isaacson PG. Gastric MALT Iymphoma: from concept to cure. Ann Oncol 1999;10:637-45.

28. Kim SW, Lim DH, Ahn YC, et al. Clinical outcomes of radiation therapy for early-stage gastric mucosa-associated lymphoid 
tissue lymphoma. World J Gastroenterol 2013;19:6062-8.

29. Gobbi PG, Corbella F, Valentino F, et al. Complete long-term response to radiotherapy of gastric early-stage marginal zone lymphoma resistant to both anti-Helicobacter pylori antibiotics and chemotherapy. Ann Oncol 2009;20:465-8.

30. Ono $S$, Kato M, Takagi $K$, et al. Long-term treatment of localized gastric marginal zone B-cell mucosa associated Iymphoid tissue Iymphoma including incidence of metachronous gastric cancer. J Gastroenterol Hepatol 2010;25:804-9.
31. Capelle LG, de Vries AC, Looman CW, et al. Gastric MALT lymphoma: epidemiology and high adenocarcinoma risk in a nation-wide study. Eur J Cancer 2008;44:2470-6.

32. Talamonti MS, Dawes LG, Joehl RJ, Nahrwold DL. Gastrointestinal Iymphoma: a case for primary surgical resection. Arch Surg 1990;125:972-6.

33. Mittal B, Wasserman TH, Griffith RC. Non-Hodgkin's lymphoma of the stomach. Am J Gastroenterol 1983;78:780-7.

34. Eng $\mathrm{T}, \mathrm{Ha}$ CS. Image-guided radiation therapy in Iymphoma management. Radiat Oncol J 2015;33:161-71. 